\title{
Dietary behaviour of Tehranian adolescents does not accord with their nutritional knowledge
}

\author{
Parvin Mirmiran, Leila Azadbakht and Fereidoun Azizi* \\ Endocrine Research Center, Shaheed Beheshti University of Medical Sciences, PO Box 19395-4763, \\ Tehran, Islamic Republic of Iran
}

Submitted 11 October 2005: Accepted 25 April 2006: First published online 22 May 2007

\begin{abstract}
Objective: To determine the nutritional behaviour of Tehranian adolescents. Subjects and methods: This study was undertaken on 7669 adolescents ( 4070 boys and 3599 girls) of 22 junior high schools and high schools as a representative sample of Tehranian adolescents. A validated knowledge, attitudes and practices (KAP) questionnaire and a food-frequency questionnaire (FFQ) were used. Factor analysis was used to determine the key questions.

Results: The mean ( \pm standard deviation) age and body mass index of the adolescents was $14 \pm 1$ years and $27.2 \pm 11 \mathrm{~kg} \mathrm{~m}^{-2}$. Although $82 \%$ of girls and $75 \%$ of boys had good nutritional knowledge, only $25 \%$ of boys and $15 \%$ of girls had good nutritional practice. Eighty-five per cent of adolescents knew that drinking too many soft beverages resulted in overweight or obesity, but only $4.5 \%$ of them did not drink soft beverages. Although $89 \%$ of adolescents knew that crisps and corn balls are not healthy snacks, $45 \%$ of them used such snacks during their break time. Thirty-seven per cent of adolescents preferred whole-grain biscuits to creamy wafer ones but only $10 \%$ of adolescents used whole-grain biscuits as a snack. The most frequently consumed snacks among Tehranian adolescents were sausage sandwiches, cocoa cola, crisps and corn balls, creamy wafers, cakes, chocolate and toffee.

Conclusion: A low percentage of Tehranian adolescents have good nutritional behaviour and in most of them their nutritional practice does not accord with their nutritional knowledge. These results indicate the necessity of nutritional intervention in Tehranian adolescents.
\end{abstract}

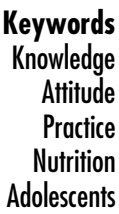

The prevalence of risk factors for non-communicable diseases has increased in both adolescents and adults in Iran. According to the results of the Tehran Lipid and Glucose Study (TLGS) ${ }^{1,2}, 18 \%$ of adolescents are overweight or obese, $12-18 \%$ have cholesterol level above $200 \mathrm{mg} \mathrm{dl}^{-1}$ and $14-17 \%$ have low-density lipoprotein cholesterol level greater than $130 \mathrm{mg} \mathrm{dl}^{-1}$. Epidemiological studies have shown that changes in lifestyle during recent years, especially changes in nutritional habits, may be responsible for increasing rates of non-communicable diseases $^{3}$. Nutritional factors have an important role in the incidence of non-communicable diseases ${ }^{4}$ and they are strong predictors of cardiovascular risk among adolescents $^{5}$. As poor nutritional habits may be formed during the teenage years, and most nutritional habits in adults result from nutritional behaviours gained during adolescence, it is very important to study the nutritional knowledge, attitudes and practices of adolescents ${ }^{3}$.

Different studies have shown that most obese or overweight adolescents are at high risk of developing noncommunicable diseases in adulthood ${ }^{6}$. Several decades have passed since nutritional education was first introduced to reduce non-communicable diseases ${ }^{7}$. Although education improves nutritional knowledge, there is often a big gap between knowledge and practice ${ }^{8}$. For health promotion to be successful, it must address the needs and aspirations of the target audience and take into consideration their current knowledge, attitudes and behavioural patterns? ${ }^{9}$. Previous studies have investigated the knowledge, attitudes and practices of Iranian adolescents with regard to iron-deficiency anaemia ${ }^{10}$ and nutritional needs ${ }^{11,12}$. But there is no study that determines the accordance between knowledge and practice in the field of non-communicable disease. Therefore the present study was conducted to determine the knowledge, attitudes and practices of Tehranian adolescents concerning the role of healthy nutrition for prevention of noncommunicable diseases.

\section{Subjects and methods}

This study was undertaken on a representative sample of 7669 Tehranian adolescents aged 10-18 years. These adolescents were randomly chosen from 22 junior high 
schools and high schools. The study was conducted within the framework of the TLGS, a prospective study performed on residents of district 13 of Tehran with the aim of determining the prevalence of risk factors for noncommunicable disease and developing a healthy lifestyle to improve these risk factors ${ }^{13}$.

A validated questionnaire was used to evaluate the knowledge, attitudes and practices (KAP) of adolescents with regard to healthy nutrition for preventing noncommunicable diseases. Variables covered by this KAP questionnaire were weight, type of fat intake, and fibre, sugar and salt intake. Knowledge questions were designed to be answered as 'yes', 'no' or 'I don't know'. The correct answer was scored as +1 , the wrong answer as -1 and 'I don't know' scored 0 . Attitude was scored from 1 to 4 as the lowest and highest scores in each question, respectively ${ }^{4}$. In practice questions, the consumption frequency of dairy, beverages, nuts, crisps, corn balls, vegetables and fruits, whole grains and refined grains was evaluated in meals and snacks separately ${ }^{4}$. The frequency of food intake was determined in the KAP questionnaire by: 1, yes, always; 2 , yes, often; 3, yes, sometimes; and 4, never. Face and content validity of the questionnaire was assessed by experts. For evaluating the reliability of the questionnaire pre-tests and post-tests were conducted one month apart; the correlation between the two tests was $r=0.7, P<0.001$. The maximum scores in the knowledge, attitudes and practices sections were 36, 28 and 64, respectively. In each part, scores of more than $75 \%$ of the maximum were considered 'good', scores of 50-75\% were considered 'fair' and scores lower than 50\% were considered 'poor'3. Thus poor, good and fair scores were as follows: $<18,>27$ and 18-27, respectively, for knowledge; $<14,>21$ and 14-21, respectively, for attitude; and $<32,>48$ and 32-48 respectively, for practice.

Usual dietary intake was assessed by using a 168-item semi-quantitative food-frequency questionnaire (FFQ). The questionnaire was administered by trained dietitians who had 5 or more years of experience in the Nationwide Food Consumption Survey project ${ }^{14,15}$. The FFQ consisted of a list of foods and a standard serving size for each (Willett format) ${ }^{16}$. In this questionnaire subjects were asked to report their frequency of consumption of a given serving of each food item during the previous year on a daily (e.g. bread), weekly (e.g. rice, meat) or monthly (e.g. fish) basis. Portion sizes of consumed foods were converted to grams using household measures ${ }^{17}$. Each food and beverage was then coded according to the prescribed protocol and analysed for content of energy and the other nutrients using Nutritionist III software (version 7.0; N Squared Computing), which was designed for evaluation of Iranian foods.

The reliability of the FFQ in this cohort was evaluated in a randomly chosen subgroup of 132 subjects by comparing nutrient consumption determined by responses to the FFQ on two occasions. The correlation coefficients for the repeatability of grain, vegetable, fruit, dairy and meat were $0.85,0.79,0.71,0.74$ and 0.70 , respectively. The FFQ also had high reliability for nutrients. For example, the correlation coefficients were 0.81 for dietary fibre, 0.75 for calcium and 0.71 for vitamin C. Comparative validity was determined by comparison with intake estimated from the average of twelve 24-hour dietary recalls (one for each month of the year). Preliminary analysis of the validation study showed that nutrients were moderately correlated between these two methods after controlling for total energy intake. These correlation coefficients were 0.69 for dietary fibre, 0.64 for vitamin $\mathrm{C}$ and 0.68 for calcium intake. Overall, these data indicate that the FFQ provides reasonably valid measures of the average long-term dietary intake ${ }^{18}$.

\section{Results}

The mean ( \pm standard deviation) age and body mass index of the adolescents was $14 \pm 1$ years and $27.2 \pm 11 \mathrm{~kg} \mathrm{~m}^{-2}$, respectively.

Table 1 shows the frequency of the adolescents' nutritional knowledge, attitude and practice scores according to sex. The mean knowledge score was $30 \pm 3.8$ (range: 17-40) in boys and $31 \pm 3.8$ (range: $18-40$ ) in girls. Attitude score was $20 \pm 4.3$ (range: 6-28) in boys and $19 \pm 4.6$ (range: 7-28) in girls. The mean score of nutritional behaviour (practice) in boys and girls was $44 \pm 6.5$ (range: 16-66) and $42 \pm 6.8$ (range: $11-64$ ), respectively. There were significant differences in the knowledge, attitude and practice scores between girls and boys $(P<0.001)$. Twenty-eight per cent of the parents were universityeducated. There was a significant positive correlation between the nutritional knowledge of students and the education level of their parents $(r=0.14, P<0.001)$. A higher percentage of girls had good nutritional

Table 1 Absolute and relative frequency of knowledge, attitude and practice scores among Tehranian adolescents

\begin{tabular}{|c|c|c|c|c|c|c|c|c|c|}
\hline & \multicolumn{3}{|c|}{ Knowledge } & \multicolumn{3}{|c|}{ Attitude } & \multicolumn{3}{|c|}{ Practice } \\
\hline & Poor & Fair & Good & Poor & Fair & Good & Poor & Fair & Good \\
\hline Boys & $4(0)^{*}$ & $885(25)$ & $2622(75)^{\star}$ & 432 (12) & $1747(49)$ & $1400(39)^{*}$ & $151(4)^{\star}$ & 2667 (71) & $910(25)^{\star}$ \\
\hline Girls & $2(0)$ & 593 (18) & 2664 (82) & 57 (17) & $1661(50)$ & 1119 (33) & 342 (10) & $2587(75)$ & $540(15)$ \\
\hline
\end{tabular}

Values in parenthesis are relative frequency.

* Significantly different compared with girls: $P<0.05$. 
knowledge ( $82 \%$ of girls vs. $75 \%$ of boys, $P<0.05$ ) but a higher percentage of boys had good nutritional attitude (39\% of boys vs. 33\% of girls, $P<0.05$ ).

The key questions of the KAP questionnaire were defined according to the results of factor analysis. The frequency of adolescents giving the correct answer to the key questions is shown in Table 2 . The results showed that $36 \%$ of adolescents did not know that sweets and candies increased weight. Fifty-six per cent of adolescents did not have correct knowledge about fish oil. Eighty-five per cent of adolescents knew that drinking too many soft beverages resulted in overweight or obesity, but only $4.5 \%$ of them did not drink soft beverages. Although 89\% of adolescents knew that crisps and corn balls are not healthy snacks, $45 \%$ of them used such snacks during their break time. Twenty-eight per cent of adolescents preferred corn ball to nut consumption. Only 37\% of adolescents consumed fresh vegetables with their meals and only $10 \%$ of them used whole-grain biscuits.

Nutrient and food group intakes of the adolescents are shown in Table 3. The results reveal that girls consumed a higher amount of saturated fatty acids than boys ( $\%$ of energy: $15 \%$ vs. $10 \%, P<0.05)$, while boys consumed a higher amount of polyunsaturated fatty acids (\% of energy: $14 \%$ vs. $10 \%, P<0.05)$. Cholesterol intake was higher in girls $\left(380 \mathrm{mg} \mathrm{day}^{-1}\right.$ for girls vs. $230 \mathrm{mg} \mathrm{day}^{-1}$ for boys, $P<0.05)$. Boys consumed a greater amount of whole grains than girls ( 83 vs. $56 \mathrm{~g} \mathrm{day}^{-1}, P<0.05$ ). Table 4 shows the food items that were eaten as snacks. Crisps were the salty snack with the highest consumption among adolescents. Creamy wafers had the first rank among sweet snacks. There was a significant correlation between nutritional knowledge and attitude scores $(r=0.24, P<0.001)$, but the correlation between nutritional knowledge and behaviour scores was weak ( $r=0.05$, not significant).

\section{Discussion}

The results of present study, conducted among a group of Tehranian adolescents, showed that only $25 \%$ of boys and
$15 \%$ of girls had good scores for nutritional practice, while $75 \%$ of boys and $82 \%$ of girls had good scores for nutritional knowledge. These results reveal a gap between knowledge and behaviour in Tehranian adolescents, as reported in other countries ${ }^{8,19,20}$. Findings from a study on Tehranian adults also indicated a sizeable gap between nutritional knowledge and behaviour ${ }^{21}$. More than half of the adults were residents of east Tehran and had moderate knowledge, whereas desirable practice was seen in only a quarter of them ${ }^{21}$.

Broad social and cultural factors play important roles in shaping food choices ${ }^{22}$. Physiological needs, body image, peer pressure, classmates' nutritional behaviour, media social norms, availability of foods, personal experiences and food preferences may be some factors. The packaging of foods is also important. The use of attractive boxes for non-nutritive salty and fatty snacks may have an important influence on food choice. There was a weak correlation between nutritional knowledge and behaviour among these Tehranian adolescents. The literature on eating behaviour and its relation to nutrition knowledge is contradictory $^{22,23}$. Some researchers have shown that nutritional knowledge is highly and positively related to nutritional behaviours, whereas others have found little correlation between nutritional knowledge and actual choices of healthy food.

In the present study, the nutritional knowledge of girls was significantly higher than that of boys. Girls in general may be more knowledgeable about food, nutrition and health and they manifest a more heightened concern about their personal and physical appearance than boys ${ }^{24}$. Yet despite their lower knowledge, boys had a greater level of good nutritional practice. In the USA and Geneva, Switzerland, the knowledge and attitude of women about diet and health were better than those of men ${ }^{8}$. However, in that study the mean scores for knowledge, attitude and practice were not very different and it seems that this significance could be an artefact because of the large sample size.

The amount of salty and sweet snacks consumed by the Tehranian adolescents was much greater than the

Table 2 Frequency of correct answers to key questions among Tehranian adolescents

\begin{tabular}{lcc}
\hline & \multicolumn{2}{c}{ Correct answer (\%) } \\
\cline { 2 - 3 } Question & Boys $(n=4070)$ & Girls $(n=3599)$ \\
\hline Knowledge & $49^{\star}$ & 61 \\
$\quad$ Does sausage have cholesterol? & $73^{\star}$ & 82 \\
Do fried and high fat foods increase your weight? & $49^{\star}$ & 56 \\
Do fruit and vegetables have an essential role in weight change? & 64 & 64 \\
Attitude & 37 & 38 \\
Which one do you prefer? Fruit juice or commercial juice & & 5 \\
Which one do you prefer? Creamy wafer or whole grain biscuits & 4 & 40 \\
Practice & 39 & 29 \\
Do you drink cocoa beverages with your meals? & $36^{\star}$ & 19 \\
Do you consume corn balls as your snack? & $33^{\star}$ & \\
Do you consume fruit as your snack? & & \\
Do you consume breakfast every day? & & \\
\hline
\end{tabular}

${ }^{*}$ Significantly different compared with girls: $P<0.05$. 
Table 3 Nutrients and food groups consumed by Tehranian adolescents

\begin{tabular}{|c|c|c|}
\hline & $\begin{array}{c}\text { Boys } \\
(n=100)\end{array}$ & $\begin{array}{c}\text { Girls } \\
(n=90)\end{array}$ \\
\hline \multicolumn{3}{|l|}{ Nutrient } \\
\hline $\begin{array}{l}\text { Saturated fatty acids (\% of } \\
\text { energy) }\end{array}$ & $10 \pm 1.2^{*}$ & $15 \pm 2.3$ \\
\hline $\begin{array}{l}\text { Polyunsaturated fatty acids (\% of } \\
\text { energy) }\end{array}$ & $14 \pm 2.9^{\star}$ & $10 \pm 2.7$ \\
\hline $\begin{array}{l}\text { Monounsaturated fatty acids (\% of } \\
\text { energy) }\end{array}$ & $7 \pm 1.3$ & $5 \pm 1.1$ \\
\hline Cholesterol $\left(\mathrm{mg} \mathrm{day}^{-1}\right)$ & $230 \pm 23^{*}$ & $380 \pm 36$ \\
\hline Protein ( $\%$ of energy) & $15 \pm 5.6$ & $13 \pm 4.9$ \\
\hline Carbohydrate ( $\%$ of energy) & $54 \pm 19$ & $57 \pm 19$ \\
\hline Sodium $\left(\mathrm{mg} \mathrm{dl}^{-1}\right)$ & $4500 \pm 136^{*}$ & $6800 \pm 145$ \\
\hline \multicolumn{3}{|l|}{ Food group } \\
\hline Whole grains $\left(\right.$ g day $\left.^{-1}\right)$ & $83 \pm 20^{*}$ & $56 \pm 17$ \\
\hline Refined grains $\left(\right.$ g day $^{-1}$ ) & $119 \pm 11$ & $130 \pm 15$ \\
\hline Vegetable (servings day ${ }^{-1}$ ) & $3.5 \pm 1.1$ & $3.9 \pm 1.2$ \\
\hline Fruit (servings day ${ }^{-1}$ ) & $3 \pm 1.2$ & $3.5 \pm 1.6$ \\
\hline Meat (servings day ${ }^{-1}$ ) & $3.0 \pm 1.1^{*}$ & $1.5 \pm 0.6$ \\
\hline Dairy (servings day ${ }^{-1}$ ) & $1.7 \pm 0.7$ & $1.6 \pm 0.6$ \\
\hline
\end{tabular}

Data are presented as mean \pm standard deviation

* Significantly different compared with girls: $P<0.05$.

amount of healthy snacks. Thus it seems that the nutrition transition ${ }^{25}$ has also transferred to adolescents. The findings of the present study reinforce those of a previous study in this field, which showed that the diet quality of $73 \%$ of Tehranian adolescents needs improvement ${ }^{26}$.

As a whole, the present study shows that nutritional knowledge is not the only factor that can influence eating behaviour. Our findings are similar to the opinions of Pirouznia $^{20}$ in this field. Considering that analysis of the

Table 4 Daily intake of food items eaten as snacks by Tehranian adolescents

\begin{tabular}{|c|c|c|}
\hline Food item & $\begin{array}{c}\text { Boys } \\
(n=100)\end{array}$ & $\begin{array}{c}\text { Girls } \\
(n=90)\end{array}$ \\
\hline \multicolumn{3}{|l|}{ Salty snacks } \\
\hline Crisps $\left(\mathrm{g} \mathrm{day}^{-1}\right.$ ) & $20 \pm 13^{*}$ & $25 \pm 15$ \\
\hline Corn balls $\left(\mathrm{g} \mathrm{day}^{-1}\right)$ & $10 \pm 7^{*}$ & $16 \pm 10$ \\
\hline Salty biscuits ( day $^{-1}$ ) & $1.0 \pm 6$ & $1.2 \pm 7$ \\
\hline \multicolumn{3}{|l|}{ Snacks full of saturated fatty acids } \\
\hline Sausage sandwiches (number week ${ }^{-1}$ ) & $5 \pm 1^{*}$ & $3 \pm 0.5$ \\
\hline \multicolumn{3}{|l|}{ Sweet snacks } \\
\hline Commercial juice (cups day ${ }^{-1}$ ) & $0.5 \pm 0.2$ & $1.0 \pm 0.3$ \\
\hline Soft beverage (cups day ${ }^{-1}$ ) & $0.5 \pm 0.9^{*}$ & $1.0 \pm 0.7$ \\
\hline Creamy wafers $\left(\right.$ g day $\left.^{-1}\right)$ & $3.5 \pm 1.0$ & $3.5 \pm 1.1$ \\
\hline Candies $\left(\right.$ g day $\left.^{-1}\right)$ & $4 \pm 2$ & $5 \pm 1.5$ \\
\hline Cakes $\left(\mathrm{g} \mathrm{day}^{-1}\right)$ & $22 \pm 5$ & $30 \pm 9$ \\
\hline Chocolate $\left(\mathrm{g} \mathrm{day}^{-1}\right)$ & $7 \pm 4$ & $8 \pm 5$ \\
\hline Toffee $\left(\right.$ g day $\left.^{-1}\right)$ & $2 \pm 0.6$ & $2 \pm 0.7$ \\
\hline \multicolumn{3}{|l|}{ Healthy snacks } \\
\hline Milk (cups day ${ }^{-1}$ ) & $0.5 \pm 0.2$ & $0.5 \pm 0.3$ \\
\hline Fruits (servings day ${ }^{-1}$ ) & $1.5 \pm 0.3$ & $1.5 \pm 0.4$ \\
\hline Nuts $\left(\mathrm{g} \mathrm{day}^{-1}\right)$ & $10 \pm 0.4^{*}$ & $2.5 \pm 0.3$ \\
\hline Dried fruits $\left(\mathrm{g}\right.$ day $\left.^{-1}\right)$ & $1.7 \pm 0.3$ & $1.6 \pm 0.4$ \\
\hline Cheese and bread (number day ${ }^{-1}$ ) & $0.5 \pm 0.2$ & $0.5 \pm 0.9$ \\
\hline
\end{tabular}

Data are presented as mean \pm standard deviation

* Significantly different compared with girls: $P<0.05$. results of a KAP questionnaire may be beneficial in health promotion programmes, there is no standard questionnaire on nutritional KAP for adolescents in Iran, which is one limitation of our study.

Besides administering a KAP questionnaire we assessed nutritional practices with a validated FFQ, which increased the validity of our results and was one of the strengths of this study. As the nutritional knowledge of Tehranian adolescents does not accord with their nutritional behaviour, nutritional intervention seems warranted. The necessity for intervention is especially clear given the nutrition transition reported in Iran in recent years ${ }^{25}$.

As most nutritional habits are confirmed in the teenage years and these habits track as nutritional preferences into adulthood, nutritional intervention according to the results of KAP questionnaires may be important in health promotion programmes. Such results might help in the future design and targeting of appropriate interventions, such as nutrition education programmes.

\section{References}

1 Azizi F, Allahverdian S, Mirmiran P, Rahmani M, Mohammadi F. Dietary factors and body mass index in a group of Iranian adolescents: Tehran lipid and glucose study -2 . International Journal for Vitamin and Nutrition Research 2001; 71: 123-7.

2 Azizi F, Rahmani M, Madjid M, Allahverdian S, Ghanbili J, Ghanbarian A, et al. Serum lipid levels in an Iranian population of children and adolescents: Tehran lipid and glucose study. European Journal of Epidemiology 2001; 17: $281-8$.

3 Harvey-Berino J, Hood V, Rourke J, Terrance T, Dorwaldt A, Secker-Walker R. Food preferences predict eating behavior of very young Mohawk children. Journal of the American Dietetic Association 1997; 97: 750-3.

4 Woo J, Leung SS, Ho SC, Lam TH, Janus ED. Dietary intake and practices in the Hong Kong Chinese population. Journal of Epidemiology and Community Health 1998; 52: 631-7.

5 Azizi F, Mirmiran P, Azadbakht L. Predictors of cardiovascular risk factors in Tehranian adolescents: Tehran lipid and Glucose Study. International Journal for Vitamin and Nutrition Research 2004; 74: 307-12.

6 World Cancer Research Fund/American Institute for Cancer Research. Food, Nutrition and the Prevention of Cancer: A Global Perspective. Menasha, WI: Banta Book Group, 1997.

7 James WPT, Ralph A, Bellizzi M. Nutrition policies in western Europe: national policies in Belgium, the Netherlands, France, Ireland, and the United Kingdom. Nutrition Reviews 1998; 55: S4-20.

8 Girois SB, Kumanyika SK, Morabia A, Mauger E. A comparison of knowledge and attitudes about diet and health among 35- to 75-year-old adults in the United States and Geneva, Switzerland. American Journal of Public Health 2001; 91: 418-24.

9 Buttriss JL. Food and nutrition: attitudes, beliefs, and knowledge in the United Kingdom. American Journal of Clinical Nutrition 1997; 65: S1985-95.

10 Keshavarz Mohammadi N, Shojaee Zadeh D, Mahmoodi M, Froozani M, Ghasemi R. Knowledge, Attitude and Practice of Adolescents about Iron Deficiency Anemia. Abstracts of nutritional projects and thesis. Tehran: National Nutrition and Food Technology Institute, 2002; 267-8 (in Farsi). 
11 Sfarjani F, Golestan B, Derakhshani K, Molabashi T. Knowledge of female adolescents about nutritional needs in Tehran. Pajoohesh Dar Pezeshki 2001; 26: 192 (in Farsi).

12 Sfarjani F, Golestan B, Rasooli B, Roosta R. Do the female adolescents have favorable knowledge about vitamin A intake? In: 7th National Nutrition Congress. Ahvaz, Iran: Ahvaz University of Medical Sciences, 2002; 91 (in Farsi).

13 Azizi F, Rahmani M, Emami H, Madjid M. Tehran lipid and Glucose Study: rationale and design. CVD Prevention 2000; 3: 242-7.

14 Kimiagar SM, Ghaffarpour M, Houshiar-Rad A, Hormozdyari H, Zellipour L. Food consumption pattern in the Islamic Republic of Iran and its relation to coronary heart disease. Eastern Mediterranean Health Journal 1998; 4: 539-47.

15 National Food Consumption Survey, National Nutrition and Food Technology Research Institute, Tehran, 1995.

16 Rimm EB, Giovanucci EL, Stamfer MJ, Colditz GA, Litin LB, Willett WC. Reproducibility and validity of an expanded selfadministered semi quantitative food frequency questionnaire among male health professionals. American Journal of Epidemiology 1992; 135: 1114-26.

17 Ghaffarpour M, Houshiar Rad A, Kianfar H. The Manual for Household Measures, Cooking Yields Factors and Edible Portion of Foods. Tehran: Keshavarzi Press, 1999 (in Farsi).

18 Esmaillzadeh A, Mirmiran P, Azizi F. Whole-grain intake and the prevalence of hypertriglyceridemic waist phenotype in Tehranian adults. American Journal of Clinical Nutrition 2005; 81: 55-63.
19 Rasanen M, Niinikoski H, Keskinen S, Tuominen J, Simell O, Viikari $\mathrm{J}$, et al. Nutrition knowledge and food intake of seven-year-old children in an atherosclerosis prevention project with onset in infancy: the impact of child-targeted nutrition counseling given to the parents. European Journal of Clinical Nutrition 2001; 55: 260-7.

20 Pirouznia $\mathrm{M}$. The correlation between nutrition knowledge and eating behavior in an American school: the role of ethnicity. Nutrition and Health 2000; 14: 89-107.

21 Mohammadi F, Mirmiran P, Bayegy F, Azizi F. Correlation between knowledge, attitude and practice regarding the role of nutrition in non communicable diseases. Pajoohesh dar Pezeshki 2002; 26: 199 (in Farsi).

22 Shephard R, Stockley L. Nutrition knowledge, attitudes, and fat consumption. Journal of the American Dietetic Association 1987; 87: 618-19.

23 Cotugna N, Subar AF, Heimendinger J, Kahle L. Nutrition and cancer prevention knowledge, beliefs, attitudes, and practices: the 1987 National Health Interview Survey. Journal of the American Dietetic Association 1992; 92: 963-8.

24 Turrell G. Determinants of gender differences in dietary behavior. Nutrition Research 1997; 17: 1105-20.

25 Ghassemi H, Harison G, Mohammad K. An accelerated nutrition in Iran. Public Health Nutrition 2002; 5: 149-55.

26 Mirmiran P, Azadbakht L, Azizi F. Diet quality adherence to the dietary guidelines in Tehranian adolescents. International Journal for Vitamin and Nutrition Research 2005; 75: 195-200. 